\title{
Fat grafting as adjuvant to reduce scars in arm
}

\author{
Katarina Andjelkov ${ }^{1,2}$, Connor John Atkinson ${ }^{3}$ \\ 'Faculty of Medicine, University of Belgrade, Belgrade 11000, Serbia. \\ ${ }^{2}$ BelPrime Clinic, University of Belgrade, Belgrade 11000, Serbia. \\ ${ }^{3}$ Faculty of Medicine, University of Leeds, Leeds LS2 9JT, UK.
}

Correspondence to: Dr. Katarina Andjelkov, BelPrime Clinic, University of Belgrade, Brane Crncevica 16, Belgrade 11000, Serbia. E-mail: kandjelkov@belprimeclinic.com

\begin{abstract}
How to cite this article: Andjelkov K, Atkinson CJ. Fat grafting as adjuvant to reduce scars in arm. Plast Aesthet Res 2018;5:18. http://dx.doi.org/10.20517/2347-9264.2017.96
\end{abstract}

Received: 28 Dec 2017 First Decision: 9 Mar 2018 Revised: 15 Mar 2018 Accepted: 26 Mar 2018 Published: 25 May 2018

Science Editor: Raúl González-García Copy Editor: Jun-Yao Li Production Editor: Huan-Liang Wu

\begin{abstract}
Aim: Brachioplasty in patients who are normal weight, with moderate skin excess and who are not accepting long scars, remains a challenge for plastic surgeons.
\end{abstract}

Methods: We present our experience in 47 patients with short scar brachioplasty in combination with posterolateral liposuction, fascia anchoring and fat grafting in the inferomedial arm in order to improve skin quality and correct minor irregularities. Patients' satisfaction rates were evaluated after 3 and 6 months following the procedure.

Results: Patients (groups Ila, Ilb and IIla according to Rohrich classification) showed high satisfaction rates with the result both after 3 and 6 months after the procedure. The results were maintained. There were 2 cases (4.2\%) of isolated wound dehiscence occurred, which were all resolved conservatively with dressings and antibiotics.

Conclusion: The technique presented in this paper has shown to be an easy and effective solution for a diverse selection of patients suffering brachial lipodystrophy. Limited scar brachioplasty only has specific applications, and should not be considered a replacement for traditional brachioplasty.

Keywords: Arm lift, brachioplasty, fat grafting, lipodystrophy

\section{INTRODUCTION}

Sagging brachial-shaped deformities are a major concern among women. At the same time it is a challenge

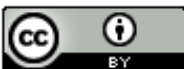

(C) The Author(s) 2018. Open Access This article is licensed under a Creative Commons Attribution 4.0 International License (https://creativecommons.org/licenses/by/4.0/), which permits unrestricted use, sharing, adaptation, distribution and reproduction in any medium or format, for any purpose, even commercially, as long as you give appropriate credit to the original author(s) and the source, provide a link to the Creative Commons license, and indicate if changes were made.

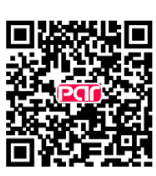


for plastic surgeons as the extension of scars limits the indications for brachioplasty and reduces patients' acceptance.

Since Correa-Iturraspe and Fernandez ${ }^{[1]}$ first described aesthetic brachioplasty in the 1950s, the procedure has become an established division of upper extremity contouring for plastic surgeons. The dramatic rise in bariatric procedures has correlated to an exponential rise in patients seeking aesthetic brachioplasty. There were 15,183 brachioplasties performed in 2010, a $4392 \%$ increase compared to the figures for $2000^{[2]}$. At the same time it is associated with significant complication rates from $25 \%-40 \%$ and revision rates between $3 \%$ $25 \%$. Most of these complications are due to the patients' dissatisfaction with the appearance of the scar ${ }^{[2,3]}$. This dissatisfaction has prompted members of the plastic surgery community to evaluate and refine current procedures, seeking a more aesthetically pleasing outcome. Using this impetus, the authors of this paper describe their current practice using fat grafting as an adjuvant to limited brachioplasty.

The majority of our patients seeking brachioplasty have typically had major weight loss after bariatric surgery or either diet and/or exercise. Yet there is still a significant portion of patients who are normal weighted but are still presenting with loose skin in the arm region due to the process of aging. These patients suffer from senile skin elastosis, but even after conventional brachioplasty, their skin still appears loose. This sub-group of brachioplasty patients always refer to a procedure with long scars as a matter of great concern. Considering this, it is a challenging task to offer those patients a satisfactory result. These patients are a minority in global brachioplasty statistics. This is probably the principal reason for a paucity of published techniques and options for these patients. However, changes in the position of incisions in continuity with the development of limited brachioplasty has demonstrated a reduced risk of idiopathic nerve and vascular damage, and improved scarring ${ }^{[4,5]}$.

We present a more conservative aesthetic procedure in order to correct only mild to moderate sagging skin, improve the skin quality, and to reduce scaring. The authors believe surgical approaches should differ depending on the amount of skin laxity and fat excess. The purpose of this paper is to demonstrate an improvement in the current short scar brachioplasty surgery, to analyse patients' satisfaction rate and to propose an option for "border line" patients that do not accept extensive scars.

\section{METHODS}

In this article we present our experience with short scar brachioplasty in combination with posterolateral liposuction, fascia anchoring and fat grafting in the inferomedial arm in order to improve skin quality and correct minor irregularities.

The patients were all normal weighted at time of operation, and did not change weight significantly pre- or post-operatively. All patients were in opposition of major scars, but still sought for contour improvement of the arm region. The limitations of the suggested technique were explained in comparison with traditional skin excision and the consent forms were signed. All patients were examined and carefully evaluated for both the amount of fat present and the amount of skin laxity in the arm region. Determination of excess was made by the pinch test. Patients with greater than $1.5 \mathrm{~cm}$ of fat detectable with the pinch test were candidates for liposuction. However, skin laxity was assessed also pinching the excess skin between the fingers, but in the diferente manner, and measuring the length of excess skin as described by Sacks ${ }^{[6]}$.

After physical examination, classification of upper arm deformity was determined for each patient according to the modified Rohrich classification system ${ }^{[4]}$. There were 3 groups of patients in our study: IIa, moderate skin excess and minimal fat excess, proximal location of skin excess; IIb, moderate skin excess and minimal fat excess, entire arm skin excess; IIIa, moderate skin and fat excess, proximal location of skin excess. 


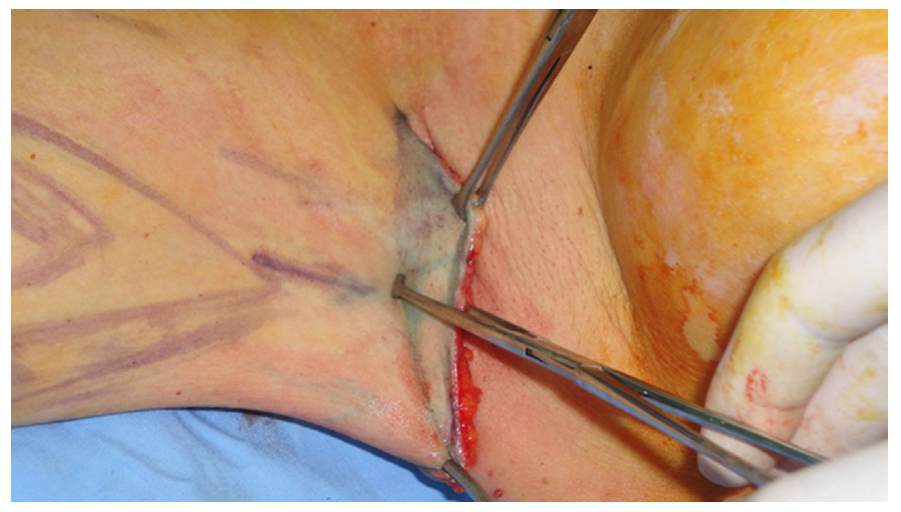

Figure 1. The redundant flap is marked using a Pitanguy marking clamp

All patients fulfilled questionnaires evaluating their satisfaction with the final result 3 and 6 months postoperatively. For those who were unable to attend the 6-month consultation, the questionnaire was completed via email or telephone call.

The amount of redundant skin and proposed areas for fat grafting were marked. The skin pattern for short scar brachioplasty typically removes skin in the longitudinal direction, with the scar well camouflaged in an axillary crease for an improved aesthetic result.

The marked areas were infiltrated with saline solution of 1:200,000 epinephrine. A decision to perform liposuction before skin excision was patient specific, depending on quantity of fat deposit (pinch test $>1.5 \mathrm{~cm}$ ) and amount of skin laxity ${ }^{[4]}$. This was found to be necessary in the majority of cases classified as IIIa and sometimes in IIa. Liposuction was performed in the deeper planes of the subcutaneous tissue at the anterior and posterolateral parts of arm using Tulip 3.0 cannulas (Tulip Medical Products, San Diego, USA), and fat was processed using Puregraft ${ }^{\circ}$ system (Bimini Technologies LLC, San Diego, USA). After purification, an average amount of $40 \mathrm{~mL}$ per arm is injected into the anteromedial aspect of the upper arm using Tulip injectors $1.2 \mathrm{~mm}$. Fat grafting was performed in several layers, both superficial and deep; with the aim to promote an expansion effect and encourage skin regeneration in the local region.

The demarcated flap is undermined and elevated superficially to the brachial aponeurosis and an axillary fascial anchoring technique was performed as described by Lockwood ${ }^{[5]}$. The use of fascial anchoring is advantageous, ensuring the axilla maintains its contour. The redundant flap is marked using a Pitanguy marking clamp, and a subsequent skin excision is performed as shown in the Figure 1.

For all patients we compiled information regarding their age, upper arm classification system and their satisfaction rate 3 and 6 months post-operatively (graded as excellent, good and as fair result). Statistical analysis of the data was performed using SPSS software and modern statistical methods.

\section{RESULTS}

In a course of 7 years (2009-2016) we treated 47 patients with this technique. All patients were female. Age ranged between 45 and 65 years (average $55.2 \pm 5.2$ ). The surgical indication for all patients was senile elastosis, or lipodystrophy of the upper arms. There was no significant statistical difference in the age distribution of patients in the group, and also in number of patients in each group $(P=0.212)$, which shows homogenous grouping when observing the age and upper arm deformity.

Our patient population according to the upper arm lipodystrophy classification is presented in Figure 2. The satisfaction rates after 3 and 6 months after the surgery and their distribution depending on the upper arm 


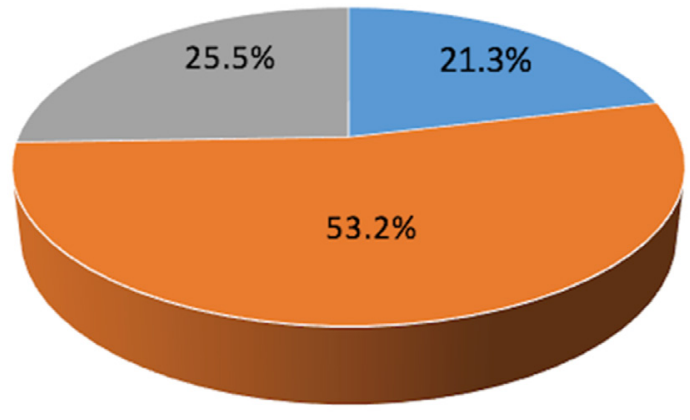

- Ila $\quad$ IIb $=$ III

Figure 2. Patients' classification of upper arm skin and fat excess according to the Rohrich classification system

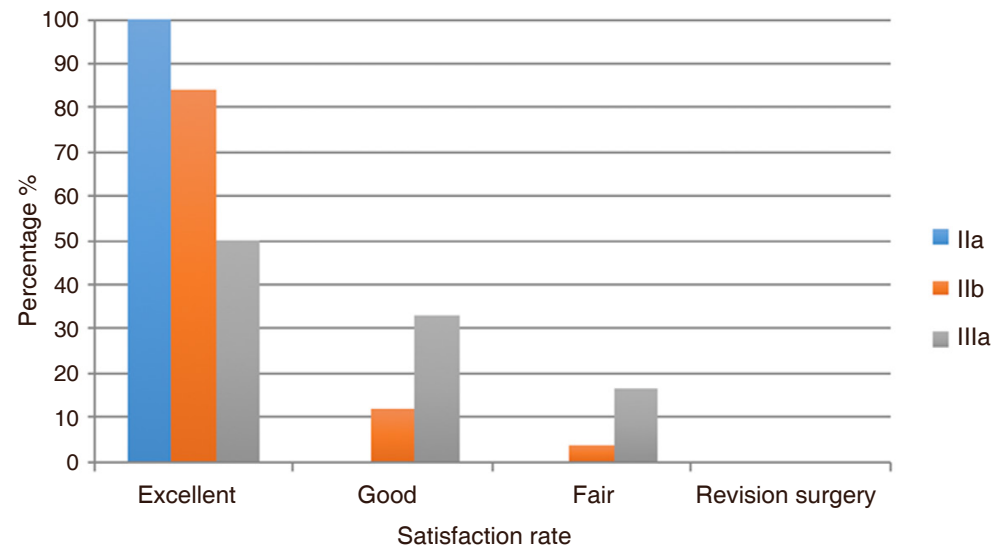

Figure 3. Patients' satisfaction rates with the result 3 months after the surgery

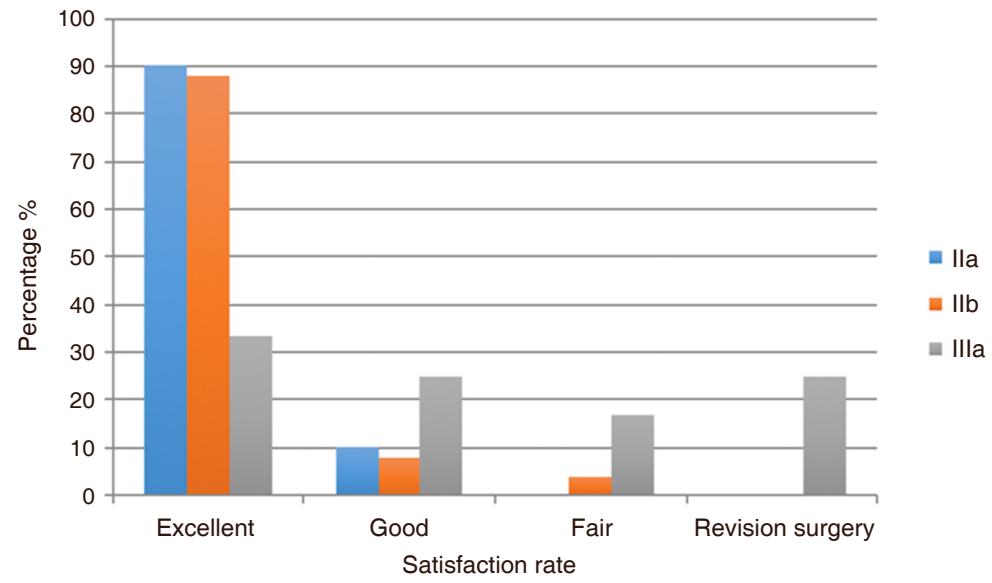

Figure 4. Patients' satisfaction rates with the result 6 months after the surgery

classification are presented in Figures 3 and 4. There was high statistically significant negative correlation in between grade and patients' satisfaction with the final result $(P<0.001)$. The higher the grade, the lower the satisfaction rate was.

After comparing satisfaction rates 3 and 6 months after the surgery, there was no significant difference in patients' satisfaction with final result $(P=0.096)$, which is very encouraging since it demonstrates that results 
are maintained.

In groups IIa and IIb the final surgical result 6 months after the surgery was considered good or excellent by more than $88 \%$ of patients, and no revision surgeries required. Patients were satisfied with the whole aspect of upper arm contouring, specifically with the hidden scar and improvement of the skin quality in areas where the fat grafting was performed. Satisfaction of the final surgical result for group III was graded as either good or excellent in $58.3 \%$ after 6 months.

There were no significant complications. Two cases (4.2\%) of isolated wound dehiscence occurred, which were all resolved conservatively with dressings and antibiotics.

\section{DISCUSSION}

The increased number of post-bariatric patients has popularised a whole range of body contouring procedures. Great weight loss is coupled with increased overall body skin laxity. When considering brachioplasty for this group of patients, the usual findings of severe brachial ptosis and skin laxity, with relatively little amount of adipose tissue are observed. The only suitable technique for these patients is traditional brachioplasty with or without extension depending on the quantity of excess chest $\operatorname{skin}^{[7-9]}$. There is no doubt among surgeons in the required treatment of this group of patients classified as group IIc and III by Rohrich Classification System, or group III and IV by Teimourian and Malekzadeh ${ }^{[10]}$.

Also there is unique opinion when good skin quality is present with moderate amount of fat excess. Solely liposuction of the upper arm is the treatment choice of this group, known as group $\mathrm{I}^{[7]}$.

However, when it comes to classification and treatment of patients in-between these two extreme groups, there are certain differences in approach. Surgical treatment ranges from limited incision, limited incision with liposuction to the traditional brachioplasty ${ }^{[7,11]}$. Furthermore, there are several methods described in literature that address the moderate skin laxity in upper arms with reduced scars such as laser-assisted liposuction in order to provoke skin retraction ${ }^{[12]}$. The idea of augmentation brachioplasty using small silicone implants has also been preconized by some plastic surgeons ${ }^{[13]}$. Importantly, the use of concomitant procedures does not significantly increase complication rates, and we believe our proposed use of fat grafting preserves this opinion ${ }^{[2,9,13]}$.

The regional anatomy favours our proposed operation, since there are no vascular or nerve structures in the trajectory of the incision, nor are these structures localised under or over the muscle; that could be impaired by compression exerted by the inclusion ${ }^{[13]}$. This technique can be used in selected cases of biceps brachii hypoplasia associated or not with a low degree of skin flaccidity in the posterior region of the arm. The volume augmentation in the anterior direction submits the posterior skin to traction.

Fat has well known filling and regenerative properties. It aids in the correction of sagging skin and improves skin quality, with only a minimal scar requirement. Furthermore, advantages of low complication rates, minimal surgical and recovery downtime, and in addition to good satisfaction and acceptance rate among patients have been reported. The described technique of harvesting, processing and injecting the fat provided predictable results that were maintained along the first year after small incision brachioplasty. This technique ensures an even contour is maintained, promoting patient satisfaction with the final result.

Three cases (6.4\%) of revision surgery after 6 months were required in our patient population, all of whom belonged to group III. For all revision cases we performed traditional brachioplasty in order to remove the remaining excess skin. In consideration of treating those patients classified as group III, it is imperative to analyse the skin elasticity. Limited brachiolpasty procedures only address skin excess in the longitudinal 


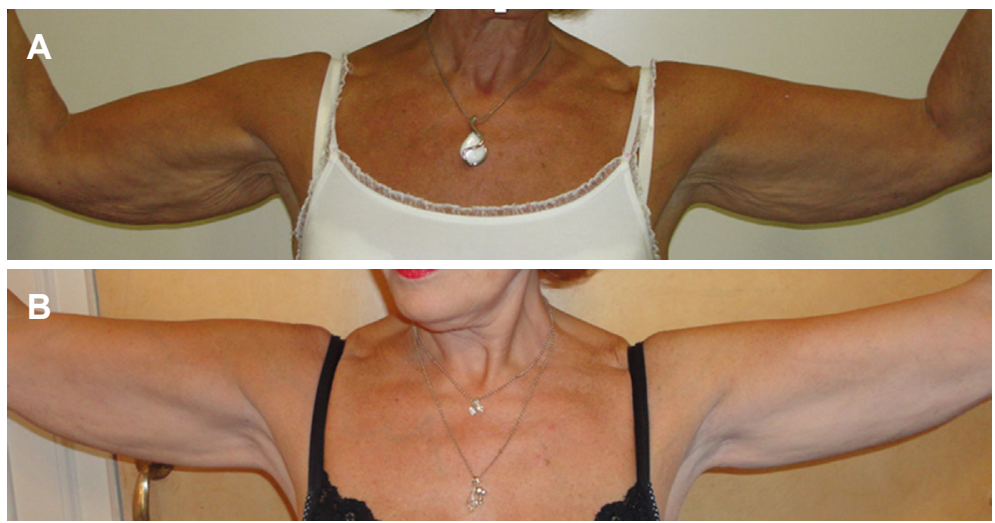

Figure 5. A 67-year-old patient, before (A) and 1 year after (B) short scar arm lift in combination with fat grafting

direction, whereas as those procedures extending across the brachial sulcus towards the elbow can address skin excess in both a longitudinal and transverse plane ${ }^{[14]}$. Therefore this discussed technique can falter in accommodating patients with high skin excess. This emphasises the importance of patient selection.

Relatively high satisfaction rate after 6 months for the group III confirms the use of this surgical procedure as an option for selected cases within this group, especially when patients do not accept long scars.

In addition to the importance of patient selection in the success of this procedure, careful pre-operative assessment and appropriate skin markings are decisive ${ }^{[11]}$. With appropriate attention to these factors, the final aesthetic result should satisfy patient demands [Figure 5].

Major weight-loss patients are not good candidates for this surgery because of poor skin contraction potential. That is why they were not included in this study.

In conclusion, this modified short scar brachioplasty technique, as proposed by the authors, has demonstrated its invaluable place among upper extermity contouring armaentarium. The technique has shown to be an easy and effective solution for a diverse selection of patients suffering brachial lipodystrophy (IIa, IIb, IIIa). Patients classified in groups IIa and IIb reported high acceptance and satisfaction rates. When considering its application to a group IIIa patients, it is necessary to explain in detail its limited application in achieving satisfactory reduced brachial sagging. The technique discussed offers further refinement in the development of upper extremity contouring. Limited scar brachioplasty only has specific applications, and should not be considered a replacement for traditional brachioplasty ${ }^{[14,15]}$.

\section{DECLARATIONS}

\section{Authors' contributions}

Principal surgeon and the first author of the paper: Andjelkov K

Participated in data research, writing and processing the data: Atkinson CJ

\section{Data source and availability}

This is a retrospective study. Patients' data were collected from their protocols. All patients were operated in "Hospital Colic", Belgrade, Serbia.

\section{Financial support and sponsorship}

None. 


\section{Conflicts of interest}

The part of this work was presented at 11th Annual Meeting IFATS New York, November 21-23, 2013. Authors declare that they have no conflicts of interest that could inappropriately influence this work.

\section{Patient consent}

All patients signed consent form prior to the surgery and were informed in detail about the whole procedure.

\section{Ethics approval}

The ethical approval was obtained by the Ethical Committee in the Hospital "Colic" issued under number $021 / 14$.

\section{Copyright}

(c) The Author(s) 2018.

\section{REFERENCES}

1. Correa-Iturraspe M, Fernandez JC. Dermolipectomia braquial. Prensa Med Argent 1954;34:2432-6.

2. Zomerlei TA, Neaman KC, Armstrong SD, Aitken ME, Cullen WT, Ford RD, Renucci JD, VanderWoude DL. Brachioplasty outcomes: a review of a multipractice cohort. Plast Reconstr Surg 2013;131:883-9.

3. Nguyen AT, Rohrich RJ. Liposuction-assisted posterior brachioplasty: technical refinements in upper arm contouring. Plast Reconstr Surg 2010;126:1365-9.

4. Appelt EA, Janis JE, Rohrich RJ. An algorithmic approach to upper arm contouring. Plast Reconstr Surg 2006;118:237-46.

5. Lockwood T. Brachioplasty with superficial fascial system suspension. Plast Reconstr Surg 1995;96:912-20.

6. Sacks AC. Grading system simplifies brachioplasty decisions. Cosmet Surg Times 2003;6:8.

7. Knoetgen J, Moran SL. Long-term outcomes and complications associated with brachioplasty: a retrospective and cadaveric study. Plast Reconstr Surg 2006;117:2219-23.

8. Pascal JF, Le Louam C. Brachioplasty. Aesthet Plast Surg 2005;29:423-9; discussion 430.

9. Gusenoff JA, Coon D, Rubin JP. Brachioplasty and concomitant procedures after massive weight loss: a statistical analysis from a prospective registry. Plast Reconstr Surg 2008;122:595-603.

10. Teimourian B, Malekzadeh S. Rejuvenation of the upper arm. Plast Reconstr Surg 1998;102:545-51.

11. Rees LS. Brachioplasty with limited scar. Clin Plast Surg 2014;41:753-63.

12. Goldman A, Wollina U, de Mundstock EC. Evaluation of tissue tightening by the subdermal Nd: YAG laser-assisted liposuction versus liposuction alone. J Cutan Aesthet Surg 2011;4:122-8.

13. Dini GM, Ferreira LM. Augmentation brachioplasty. Plast Reconstr Surg 2006;117:2109-11.

14. Abramson DL. Minibrachioplasty: minimizing scars while maximizing results. Plast Reconstr Surg 2004;114:1631-4.

15. Trussler AP, Rohrich RJ. Limited incision medial brachioplasty: technical refinements in upper arm contouring. Plast Reconstr Surg 2008;121:305-7. 